\title{
Effect of COVID-19 on the Working of a Tertiary Care Hospital
}

\author{
Mahmood Ayyaz, Usman Ismat Butt, Muhammad Umar, Wasim Hayat Khan, Malik Ramzan Kashif and \\ Zulqarnain Hyidar
}

Surgical Unit 1, Services Institute of Medical Sciences / Services Hospital, Lahore, Pakistan

\begin{abstract}
Objective: To evaluate the effect of COVID-19 on the working of a tertiary care hospital.

Study Design: Audit study.

Place and Duration of Study: Services Hospital, Lahore from $1^{\text {st }}$ March to $30^{\text {th }}$ June 2020.

Methodology: We calculated and compared various parameters of hospital working. Two time periods were selected. The study period was defined as the time after first confirmed case of COVID-19 in Pakistan. The control period was defined as one year prior to the first case being reported, taken from 1st March 2019 to 29th February, 2020. The parameters we studied included were number of number of hospital admissions, emergency patients, OPD patients, major surgeries, total surgeries, radiological investigations done, laboratory investigations done, births and mortalities. All parameters were calculated by taking monthly average during each time period and then compared.

Results: A decrease in almost all parameters was seen when the cases of the two time periods were compared. There was a decrease in the average hospital admission by $51 \%$, while the patients seen in OPD fell by almost $60 \%$. A slight decrease of $25 \%$ was seen in the cases presenting to the emergency. The most marked decrease was in the elective surgeries, which was $66 \%$ closely followed by average monthly mortality which decreased by $64 \%$. Average monthly minor surgeries and births were decreased by $33 \%$ and $35 \%$, respectively.

Conclusion: There had been a decrease in the number of patients presenting to the hospital across the board with the most marked increase being in elective surgeries.
\end{abstract}

Key Words: COVID-19, Hospital working, Patient load, Elective surgery.

How to cite this article: Ayyaz M, Butt UI, Umar M, Khan WH, Kashif MR, Hyidar Z. Effect of COVID-19 on the Working of a Tertiary Care Hospital. J Coll Physicians Surg Pak 2020; 30(JCPSPCR):CR164-CR167.

\section{INTRODUCTION}

A case of pneumonia of unknown etiology appeared in Wuhan, China in December, 2019. Gradually, it spread not just across China but the whole world. Analysis of specimen revealed that the disease was due to a novel coronavirus. It mainly effects the respiratory system. It was designated as severe acute respiratory coronavirus-2 (SARS-COV2) by the international Committee on Taxonomy of Virus. The WHO designated it as coronavirus disease (COVID-19). ${ }^{1}$ On the $12^{\text {th }}$ of March 2020, it was declared as a pandemic by the WHO. ${ }^{2}$

On $26^{\text {th }}$ February 2020, the first confirmed case was reported in Pakistan in the city of Karachi. Within a week, the first case in Punjab had also been reported. ${ }^{3}$

Correspondence to: Dr. Usman Ismat Butt, Department of Surgery Unit 1, SHL, Services Insitute of Medical Sciences, Services Hospital, Lahore, Pakistan

E-mail: usmanismatbutt@yahoo.com

Received: August 02, 2020; Revised: October 03, 2020;

Accepted: November 26, 2020

DOI: https://doi.org/10.29271/jcpsp.2020.JCPSPCR.CR164
The stress and burden of the disease has been felt even by the best of the healthcare systems. On March 11, the Italian College of Anesthesia, Analgesia, Resuscitation, and Intensive Care was published guidelines for rationing care. ${ }^{4}$ In America, the Centers for Medicare and Medicaid Services (CMS) announced that all elective surgeries, non-essential medical, surgical, and dental procedures be delayed. ${ }^{5}$ Similarly, in Australia there was a suspension of elective surgeries. ${ }^{6}$ There was a drastic shift in the working of the NHS in UK with reduction in non-COVID emergencies, delay in elective surgeries, shift to telemedicine and a general reduction in overall number of patients. ${ }^{7}$

In Pakistan, SKMH had to temporarily close further intake of cancer patients. ${ }^{8}$

The study place of this audit is a tertiary care hospital in Lahore. Having a capacity of 1450 , it is one of the biggest hospitals in the province of Punjab. Located in the heart of the city, it provides services not only to the residents of the city but also serves as referral centre. It has also been declared as a COVID-19 care facility.

Such impact of COVID-19 on the working of hospitals in Pakistan was not quantified to the best of authors' knowledge. Therefore, 
the aim of this study was to perform an audit of the working of the hospital before and during COVID-19, to quantify the effect of COVID-19.

\section{METHODOLOGY}

A retrospective analysis of the electronic records was conducted at Services Hospital, Lahore to evaluate the patients presenting to different departments. There is electronic record system at our hospital, through which the record is kept and retrieved. With the help of this record and the hospital IT department, various parameters of hospital working were calculated and compared.

Two time periods were selected. The study period was defined as the time after first confirmed case of COVID-19 in Pakistan, i.e. $1^{\text {st }}$ March to $30^{\text {th }}$ June, 2020 . The control period was defined as one year prior to the first case being reported, i.e. $1^{\text {st }}$ March 2019 to $29^{\text {th }}$ February, 2020. The parameters compared between the study period and control period include average monthly hospital admissions, emergency patients, OPD patients, major surgeries done, births, radiological and laboratory investigations, and average monthly mortalities.

First, the total number was calculated for each of the above mentioned parameters and then monthly average was obtained by dividing the sum with the number of months. Monthly average of each parameter from 1st March 2019 to $29^{\text {th }}$ February, 2020 was obtained by dividing the sum by 12 . We then calculated the monthly average of the four months during pandemic, i.e. $1^{\text {st }}$ March to $30^{\text {th }}$ June 2020. Various parameters were compared to estimate the effect of the pandemic on hospital working.

Table I: Comparison of pre-COVID parameters with COVID era parameters.

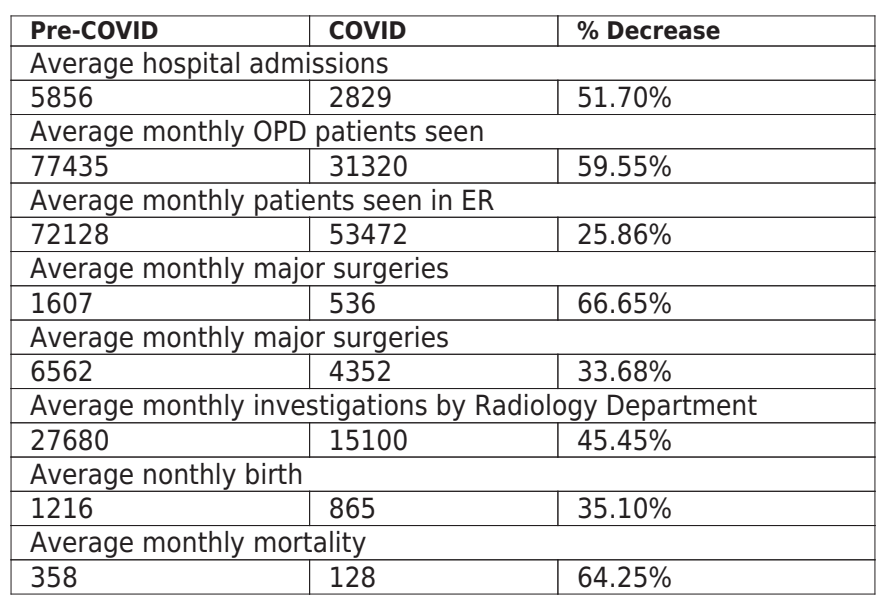

\section{RESULTS}

A decrease in almost all parameters was seen. There was a decrease in the average hospital admission by $51 \%$, while the patients seen in OPD fell by almost $60 \%$. A decrease of $25 \%$ was seen in the cases presenting to the Emergency. The most marked decrease was in the elective surgeries, which was $66 \%$ closely followed by average monthly mortality which decreased by $64 \%$. Average monthly minor surgeries and births saw decrease of $33 \%$ and $35 \%$, respectively. Results are summarised in Table I and Figures 1-3.

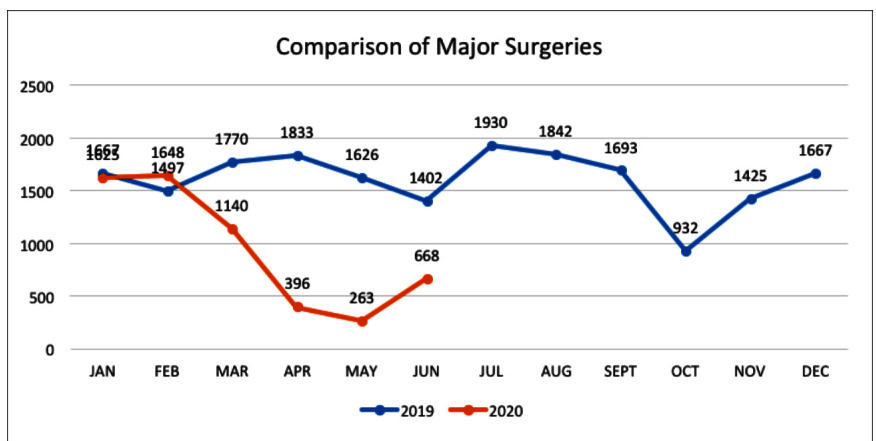

Figure 1: Comparison of major surgeries during 2019 and 2020.

\section{Break Down of Radiology Working}

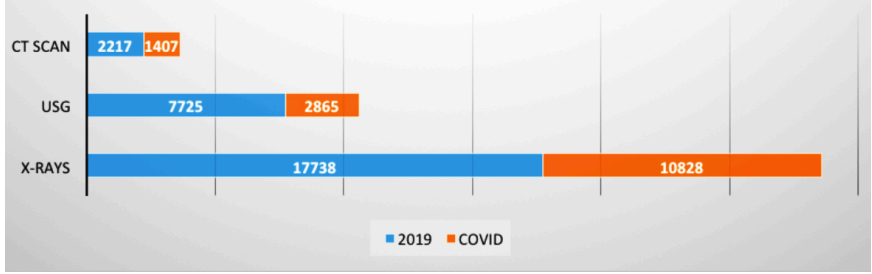

Figure 2: Radiology working.

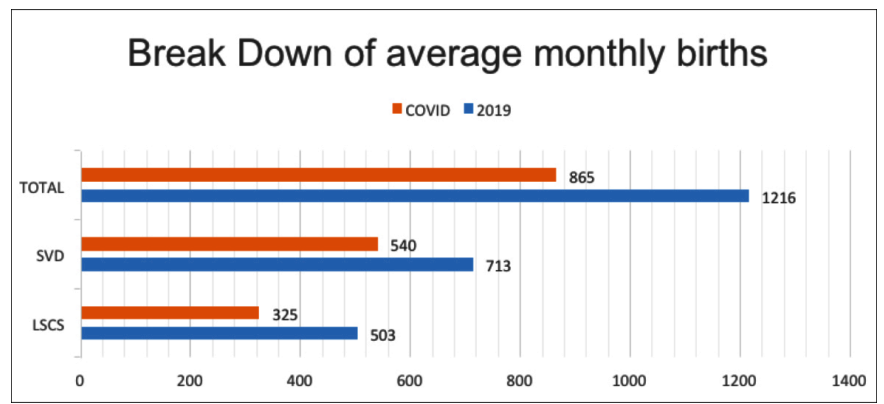

Figure 3: Average monthly births and mode.

\section{DISCUSSION}

In order to deal with the COVID-19, a number of measures have been adopted worldwide. Social distancing and selective and general social containment have also been adopted. The response in our country is varied from strict to selective containment. At the same time, there has been re-organisation of the healthcare system to cope with the expected wave of patients. Steps have been taken to ensure to provision of routine care to the patients to continue as before in a smooth fashion. However, some changes in the pattern of hospital working have been noted during this period. This change seems to have been noted by researchers in other countries, as well. ${ }^{9-12}$

On the basis of our comparison, it was seen that the number of admissions to the hospital during the months of the pandemic was almost reduced to half that during the previous year. The effect was even more pronounced when COVID-19 related admissions were not taken into consideration (Table I).

Similarly, the monthly OPD patients seen at the hospital had a 
drastic decrease to almost half before the pandemic. The OPD remained closed for two weeks during the complete lockdown imposed by the government at the end of March. ${ }^{13}$ However, despite complete resumption of OPD services at the start of April, the patient presentation remains low and the difference cannot be attributed solely to this closure (Table 1). The number of patients seen in the Emergency Department was also less. However, this reduction was less marked as compared to the other departments, being only $25 \%$ reduction (Table I). The decrease in the number of elective cases perhaps showed the most marked decrease. There was an almost $67 \%$ decrease in the number of major surgeries. Minor surgeries dropped by $34 \%$ (Table I, Figure 1). Such a decrease was expected since there has been a shift from the elective surgeries towards the pooling and usage of available resources for the management of COVID-19 with some suspension of elective cases.

Considering the investigative output of the hospital, there was an expected reduction in all fields. Radiological and laboratory investigations were almost reduced by half during the study period (Table I, Figure 2).

Most surprisingly when the gynecological and obstetric department was evaluated, there was an almost $30 \%$ reduction in the number of cases. Not only the elective C-sections but the number of natural births was also reduced. One can only infer that there is a tendency of patients to avoid the hospitals during the pandemic (Tablel, Figure 3).

Perhaps the most surprising finding was the mortality rate. Before the pandemic, the average monthly mortality was 358 which fell to 126 during the pandemic months - an almost $65 \%$ decrease even after including the COVID positive patients. This was somewhat unexpected as compared to the other parameters which would not have suggested such a big decrease.

These findings are in line with observations made in other parts of the world where there has been a reduction of patients, 10,12 although the exact cause of reduction in number of emergency cases is debatable. We can speculate that as a result of lockdown, the daily movement of the large number of people that took place halted; and as a result, there was a fall in the number of motor vehicle accidents. Reduction in consumption of meals from outside, perhaps led to decreased incidence of abdominal pathologies suchastyphoid, appendicitis and symptomatic gallstones. Relief from the daily stress might also have played a role in reduction of cases. ${ }^{14}$

This study gives support to the fact that there has been a decrease in patient load of the hospitals in our country as a result of the COVID-19 pandemic. Even with the resumption of services, it seems that there is a tendency among patients to avoid hospitals. There might be a rebound increase in the number of patients presenting; with risk of healthcare systems being overwhelmed by the complications due to delay. ${ }^{15}$

\section{CONCLUSION}

COVID-19 has caused a reduction in number of other cases being seen at the hospital. The exact factors behind it are uncertain.

\section{ETHICALAPPROVAL:}

Approval from Head of the Institute taken prior to conduction of audit.

\section{CONFLICT OF INTEREST:}

Authors declared no conflict of interest.

\section{AUTHORS' CONTRIBUTION:}

AM, BUI, UM, KMR: Contributed to the conception of design of study, acquisition, analysis, interpretation of data. BUI, KWH, $\mathrm{HZ}$ : Involved in drafting the work. All authors gave approval of final version of draft and agree to be accountable for all aspects of work.

\section{REFERENCES}

1. Hengbo Zhu, Li Wei, Ping Niu. The novel coronavirus outbreak in Wuhan, China. Glob Health Res Policy 2020; 5:6. Doi: 10.1186/s41256-020-00135-6.

2. WHO Director-General's opening remarks at the mission briefing on COVID-19 (12 March 2020). Geneva: World Health Organization; 2020. (http://www.who.int/dg/ speeches/detail/who-director-general-s-opening-remarksat-the-mission-briefing-on-covid-19---12-march-2020).

3. Ali MG, Ahmad MO, Husain SN. Spread of coronavirus disease (COVID - 19) from an outbreak to pandemic in the year 2020. AJRID 2020; 3(4):37-51. doi.org/10.9734/ ajrid/2020/v3i430135

4. Cavallo JJ, Donoho DA, Forman HP. Hospital capacity and operations in the coronavirus disease 2019 (COVID-19) pandemic - planning for the nth patient. JAMA Health Forum 2020; doi:10.1001/jamahealthforum.2020.0345.

5. Diaz A, Sarac BA, Schoenbrunner AR, Janis JE, Pawlik TM. Elective surgery in the time of COVID-19. Am J Surg 2020; 219(6):900-2. doi:10.1016/j.amjsurg.2020.04.014.

6. Wielogórska NL, Ekwobi CC. COVID-19: What are the challenges for NHS surgery? Curr Probl Surg 2020; 57(9):100856. doi:10.1016/j.cpsurg.2020.100856.

7. CovidSurg Collaborative. Elective surgery cancellations due to the COVID-19 pandemic: Global predictive modelling to inform surgical recovery plans. British J Surg 202; doi: 10.1002/bjs.11746.

8. Yusuf A. Cancer care in the time of COVID-19: A perspective from Pakistan. Ecancermedicalscience 2020; 14:1026. doi:10.3332/ecancer.2020.1026.

9. De Filippo O, D'Ascenzo F, Angelini F. Reduced rate of hospital admissions for ACS during Covid-19 outbreak in Northern Italy. N Engl J Med 2020; 383(1):88-9. Doi: 10.1056/NEJMc2009166.

10. Butt AA, Kartha A, Asaad N, Azad AM, Bertollini R, AbouSamra AB. Impact of COVID-19 upon changes in emergency room visits with chest pain of possible cardiac origin. $B M C$ Res Notes 2020; 13(1):539. doi:10.1186/s13104020-05381-y.

11. Butt AA, Azad AM, Kartha AB, Masoodi NA, Bertollini R, Abou-Samra $A B$. Volume and acuity of emergency department visits prior to and after COVID-19. J Emerg Med 
2020; S0736-4679(20)30855-6. doi:10.1016/j.jemermed. 2020.08.013

12. Liao JM. COVID-19 recovery will involve strategy, not just operational effectiveness. J Am Coll Radiol 2020; 17(10): 1334-6. doi:10.1016/j.jacr.2020.06.013.

13. Ayyaz M, Chima KK, Butt UI. Combating COVID 19 in a public sector hospital in Pakistan. Ann Med Surg (Lond)
2020; 60:372-9. doi:10.1016/j.amsu.2020.10.041.

14. Salleh MR. Life event, stress and illness. Malays J Med Sci 2008; 15(4):9-18

15. Al-Jabir A, Kerwan A, Nicola M. Impact of the coronavirus (COVID-19) pandemic on surgical practice - Part 2 (surgical prioritisation). Int J Surg 2020; 79:233-48. doi:10.1016/ j.ijsu.2020.05.002. 